\title{
Properly designed effort management for highly fluctuating small pelagic fish populations: a case study in a purse seine fishery targeting chub mackerel
}

\author{
Momoko Ichinokawa*, Hiroshi Okamura \\ National Research Institute of Fisheries Science, Fisheries Research Agency, 2-12-4 Fukuura, Kanazawa-ku, Yokohama, \\ Kanagawa 236-8648, Japan
}

\begin{abstract}
Proper fisheries management is difficult in fisheries targeting small pelagic fish that are subject to climate-induced oceanic regime shifts. A favourable regime tends to induce capacity investments, but the results of these investments turn out to be irreducible overcapacity under the next unfavourable regime. The Japanese purse seine fishery studied here, which targets small pelagic fish, is a typical example of such overcapacity. However, we demonstrate that this fishery represents a best practice of properly designed effort management in recent years through its quantitative evaluation. Generalized linear mixed models (GLMMs) applied to daily logbook data revealed that effort restrictions on daily purse seine operations (in terms of the duration and the total number of operations per ship and day) significantly reduced total fishing efforts on chub mackerel. Stochastic simulations based on the parameters estimated in GLMMs quantified the extent of the potential catch reduction by the effort reductions at approximately $20 \%$. Combined with the effect of another concurrently implemented management measure, i.e. day closures, the net effects of the effort management on the total catch reduction were estimated at $30 \%$. Because the quota uptake percentages in this fishery were $60-80 \%$ during the study period, we conclude that the effort management helped avoid overshooting of the quota and consequent seasonal closures.
\end{abstract}

KEY WORDS: Input control - Effort limitations · Race to fish · Catch shares

\section{INTRODUCTION}

The population dynamics of small pelagic fish is known to be strongly dependent on climate-induced oceanic regime shifts (Lluch-Belda et al. 1989). The highly fluctuating nature of this dynamics makes it difficult to manage the population as expected. For example, the increase in the population abundance under a favourable regime induces capacity investments in fisheries targeting the population. However, when the regime becomes unfavourable, the results of these investments turn out to be irreducible overcapacity and lead to the overfishing of other species.

${ }^{*}$ Corresponding author: ichimomo@fra.affrc.go.jp

${ }^{\S}$ Advance View was available online September 6, 2018
A Japanese purse seine fishery targeting small pelagic fish, primarily Japanese sardine and chub mackerel, is a typical example (Fig. 1). Japanese sardine experienced a rapid increase in abundance during the 1980s. The maximum estimated total biomass during the sardine bloom was 20 million metric tons in 1987, approximately 5 times larger than the 4 million metric tons estimated in 1976 (Yukami et al. 2017a). During that period, purse seiners competed to build new, large-scale transport ships (Makino 2011). However, the sardine biomass went into sharp decline around the early 1990s, to less than 1 million metric tons in 1994 (Fig. 1, Yukami et al. 2017a). As a

() The authors 2019. Open Access under Creative Commons by Attribution Licence. Use, distribution and reproduction are unrestricted. Authors and original publication must be credited. 

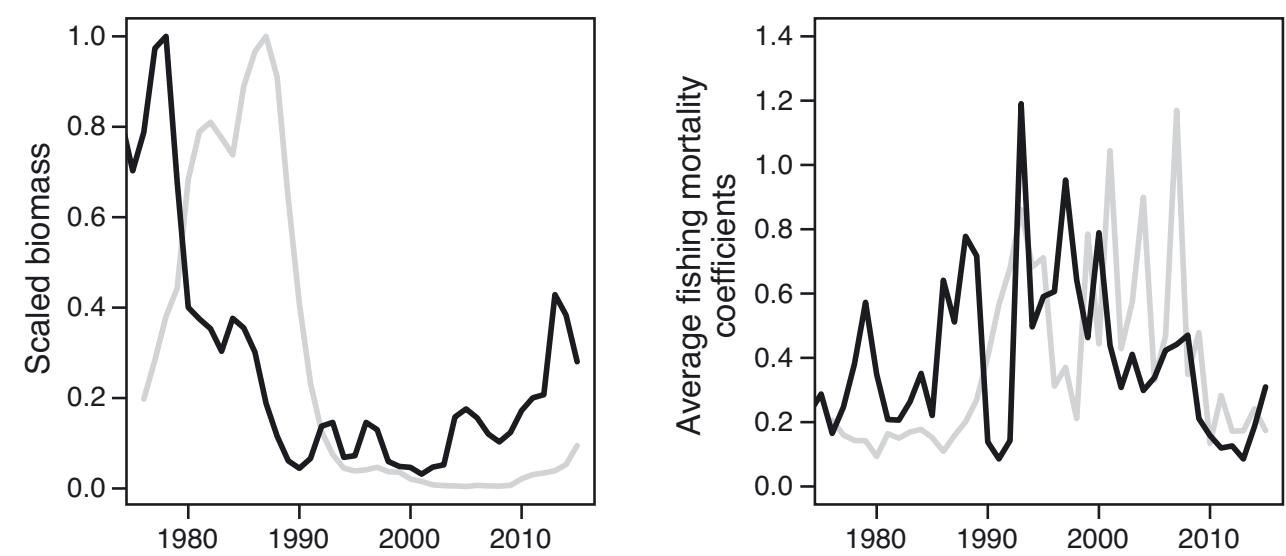

Fig. 1. Historical total biomass (left) and fishing mortality coefficients as averaged among the ages (right) of the Pacific stocks of Japanese sardine (gray) and chub mackerel (black) (Yukami et al. 2017a, Yukami et al. 2017b). The total biomass was scaled by dividing the historical maximum. The maximum biomass of Japanese sardine is 20 million metric tons, and it is approximately 4 times larger than the maximum for chub mackerel

result, the heavy fishing pressure from purse seiners gradually shifted to chub mackerel and fishers continued to overfish the stock until the early 2000 s (Kawai et al. 2002). During this period, $80-90 \%$ of the chub mackerel that were caught were immature fish, so there was no chance for the stock to recover, even though strong year classes were observed in 1992 and 1996 (Katsukawa 2005).

A similar phenomenon is often observed in fisheries stocks (Hardin 1968, Ludwig et al. 1993), and the over-expansion of the fishing capacity usually results in race-to-fish behavior by fishers; there are competing global quotas and shortened fishing periods (Morgan 1997, Beddington et al. 2007, Birkenbach et al. 2017). One of the most important objectives in fisheries science is to find a way to avoid this race-to-fish behavior, recover the reduced stock, and rebuild the ill-managed fisheries. Catch shares, that is, the allocation of a global quota to individual fishing units, has attracted attention as an effective management tool for achieving these objectives (Costello et al. 2008). Catch shares are thought to stop the race to fish by securing an individual's right to a portion of the total catch, changing the economic incentives of fishers, and reducing the race to fish among them. This management tool is becoming increasingly popular; it is helping to prevent fisheries collapses on a global scale (Costello et al. 2008).

However, the catch share approach is not the only tool that can lead to successful fisheries management (Hilborn et al. 2005). For example, effort management aimed at the direct control of fishing efforts is also expected to prevent the race to fish if it works as expected. Effort management has a long history (Pope 2009). While its potential pitfalls have been suggested, such as spillover effects, effort creep, and effort allocation in multispecies fisheries (Wilen 1979, Branch et al. 2006), effort management is advantageous to avoid discarding of over-quota catch and misreporting catches (Rijnsdorp et al. 2007). This study introduces the Japanese purse seine fishery described above as an example of the recent success of properly designed effort management.

It is usually difficult to evaluate success of effort management quantitatively. This difficulty is due to the potential changes in fisher behavior in response to management implementation (Salas \& Gaertner 2004, Fulton et al. 2011). In addition, while control experiments are conducted to quantify the effects of marine protected areas (cf. Lester et al. 2009), these experiments are not feasible for effort management. Our previous study (Ichinokawa et al. 2015) addressed this problem by describing the fleet dynamics of purse seiners with observed catch-and-effort data and by simulating their dynamics under alternative effort management scenarios. By comparing the simulated outcomes among alternative management strategies, that study quantified the effectiveness of the effort management as implemented using day closures. The quantitative evaluation of the fisheries management outcomes under diverse management objectives and strategies using computer simulation is becoming important for the success of fisheries management (Edwards \& Dankel 2016, Hillary et al. 2016).

The objective of this study was to complete a quantitative evaluation of the effort management implemented in a Japanese purse seine fishery targeting small pelagic fish, particularly by focusing effort restrictions on daily purse seine operations. To that end, 
this study had 2 specific questions. (1) Are the effort restrictions on daily purse seine operations effective at reducing the daily purse seine efforts? (2) By how much are the total catches reduced by the daily effort restrictions? To address the first question, we analyzed records of the daily purse seine operations and the effort management practices implemented from July 2009 to June 2014 by using generalized linear mixed models (GLMMs). For the second question, we conducted stochastic simulations based on the model structures and parameters estimated in the GLMMs under the assumption that the effort restrictions were looser. Finally, we clarified whether the effort management in the studied fishery was effective at maintaining the total catch under an annual quota by combining the estimation in our previous study.

\section{MATERIALS AND METHODS}

\subsection{Purse seine fishery data}

The studied purse seine fishery is operated off the northeast coast of Japan within Japan's exclusive economic zone. The recent primary target species of the fishery has been chub mackerel Scomber japonicus, but fishers occasionally catch a variety of pelagic fish such as spotted mackerel $S$. australasicus, Japanese sardine Sardinops melanostictus, and Japanese anchovy Engraulis japonicus. Spotted mackerel is often bycaught during operations targeting chub mackerel, and official catch statistics do not distinguish between the 2 species. This study defines 'chub mackerel (or mackerel)' as a mixture of the 2 species primarily consisting of chub and occasionally spotted mackerel.

All purse seine vessels operating off the northeast coast (ca. 30-40 vessels) belong to the fisheries cooperative association of the North Pacific Federation of Purse Seiners (NPFPS). The NPFPS implements a number of effort restrictions on a voluntary basis. The annual quotas are allocated to NPFPS each 1 July as approximately $60 \%$ of the annual total allowable catches (TAC) for chub and spotted mackerel. The TAC is determined from the acceptable biological catch $(\mathrm{ABC})$ based on annual scientific stock assessments (Fisheries Agency and Fisheries Research Agency of Japan 2017).

We collected the daily fishing records of all the purse seine vessels conducting operations within the administrative area of the NPFPS. These records contain information on the total amount of the catch and the species composition by each operation as well as when and where the purse seine operation was started. The data were collected from July 2009 to June 2014, corresponding to the 2009-2013 fishing years, which are defined as from 1 July to the end of June in the following year. The total annual quotas of chub mackerel allocated to the NPFPS for each of the 2009 to 2013 fishing years were 336, 356, 410, 392, and 401 thousand metric tons, respectively. The actual catches by the NPFPS according to the official statistics were 276, 257, 260, 234, and 285 thousand metric tons, respectively, corresponding to $82 \%, 72 \%, 63 \%$, $60 \%$, and $71 \%$, respectively of the allocated quotas.

We also collected information on the effort management practices implemented by the NPFPS during the same period. The primary effort management strategies were roughly categorized into 2 types. The first management type uses day closures in which all the purse seine operations targeting chub mackerel are suspended for $1 \mathrm{~d}$ following any day when the total mackerel catch exceeds a threshold level. These management effects were previously quantified by Ichinokawa et al. (2015). This study evaluated other management methods using effort restrictions on daily purse seine operations. These restrictions were placed on the duration over which purse seiners were allowed to commence their operations and set an upper limit on the total number of daily purse seine operations per vessel. Day closures and effort restrictions on daily operations have been concurrently implemented since 2004.

\subsection{Statistical analysis to test the effectiveness of effort restrictions}

We used the GLMMs to test the effects of the effort restrictions on the daily purse seine operations. The purse seine vessels that belong to the NPFPS conducted 1-3 operations during a daily purse seine trip during the study period, with subsequent fourth and fifth operations representing only $0.5 \%$ of the total operations during the observed period.

We therefore constructed 2 separate GLMMs as follows. The first model is for the second operation (second operation model) with the response variable $s O_{i}$ taking a value of 1 or 0 if the second operation caught $>0$ chub mackerel or not, respectively, after $>0$ chub mackerel were caught during the first operation on the $i$ th day. The second model is for the third operation (third operation model) with the response variable $t_{i}$ taking a value of 1 or 0 if the third operation caught $>0$ chub mackerel or not, respectively, after $>0$ chub mackerel were caught during the second op- 
eration. The response variables $s o_{i}$ and $t o_{i}$ followed Bernoulli distributions as $s o_{i} \sim \operatorname{Bernoulli}\left(s p_{i}\right)$ and $t o_{i} \sim \operatorname{Bernoulli}\left(t p_{i}\right)$, respectively. The expected values of $s p_{i}$ and $t p_{i}$ represent the probabilities of catching $>0$ chub mackerel in the second and third operations, respectively.

While probabilities $s p_{i}$ and $t p_{i}$ can be affected by a variety of factors, the focus of this study is the effect of the daily effort restrictions. These effects were examined by introducing a continuous explanatory variable of the time (hours, $h_{i}$ ) during which purse seiners were allowed to commence their operations on the ith day. We also considered the effect of the upper limit on the total number of daily purse seine operations per vessel. During the study period, the upper limit was set at 1 over a total of $21 \mathrm{~d}, 2$ over a total of $670 \mathrm{~d}, 3$ over a total of $825 \mathrm{~d}, 4$ over $1 \mathrm{~d}$, and no per-day limits over a total of $1137 \mathrm{~d}$. Although the upper limit of 1 would be the most significant for both second and third operation models, we could not introduce the effect because no second or third operations were conducted below the upper limit of 1 . The corresponding data were excluded from the statistical analysis to avoid confounding them with the factor $h_{i}$. We did not use the data when the upper limit was 4 because of insufficient data points. Therefore, 2 categorical explanatory variables, $g_{i}$ and $f_{i}$, were introduced. The variable took a value of 1 if the upper limit was 2 in the case of $g_{i}$ and 3 in the case of $f_{i}$. Theoretically, while $f_{i}$ did not have any effects on the decision by fishers in the second and third operation models, $t p_{i}=0$ whenever $g_{i}=1$ if there were no implementation errors. However, because there were a few implementation errors probably due to unexpected bycatches, we were able to incorporate the effect of $g_{i}$ into the third operation model to avoid complete separation.

We also incorporated explanatory variables of the amount of catch from the first operation $\left(C_{i}\right)$ for the second operation model and the total amount of catch from the first and second operations $\left(D_{i}\right)$ for the third operation model. Both factors were incorporated because the motivation to perform subsequent purse seine operations was likely to be affected by a larger previous catch. We also incorporated an explanatory variable representing the fish target. The targeting variable $E_{i}$ was quantified by the proportion of chub mackerel catches to the total catches for the whole month in which the ith day occurred. This variable was introduced because fishers seemed to prefer not to catch mixed species. In addition, we considered that this variable could reflect a voluntary regulation with which purse seine operations stop when squid is caught to avoid conflicts with coastal fishers for squid. We also incorporated the random effects of the fishing year $\left(Y_{i}, 2009-2013\right)$, fishing area $\left(A_{i}, 1-3\right)$, month $\left(M_{i}\right.$, January-December), and vessel $\left(V_{i}, 1-43\right)$. Fishing areas were categorized into 3 groups, namely areas north of $39.5^{\circ} \mathrm{N}$, between $37.5^{\circ}$ and $39.5^{\circ} \mathrm{N}$, and south of $37.5^{\circ} \mathrm{N}$. The latitude line at $37.5^{\circ} \mathrm{N}$ corresponds to an area where fishing has been prohibited around the Fukushima Dai-ichi nuclear plant since March 2011 (Okamura et al. 2016), and the one at $39.5^{\circ} \mathrm{N}$ was determined as the area where the remaining fishing efforts were separated roughly equally.

The second and third operation models were expressed as follows, respectively:

$$
\begin{aligned}
& \operatorname{logit}\left(s p_{i}\right)=\alpha_{0}+\alpha_{1} \log \left(h_{i}\right)+\alpha_{2} g_{i}+\alpha_{3} f_{i}+\alpha_{4} C_{i}+\alpha_{5} E_{i} \\
& +\sum_{k=1}^{15} \beta_{k}(Y \times A)_{i, k}+\sum_{k=1}^{24} \gamma_{k}(M \times A)_{i, k}+\sum_{k=1}^{57} \delta_{k}(Y \times M)_{i, k}+\sum_{k=1}^{43} \zeta_{k}(V)_{i, k} \\
& \quad \text { and } \\
& \quad \operatorname{logit}\left(t p_{i}\right)=\varphi_{0}+\varphi_{1} \log \left(h_{i}\right)+\varphi_{2} g_{i}+\varphi_{3} f_{i}+\varphi_{4} D_{i}+\varphi_{5} E_{i} \\
& +\sum_{k=1}^{15} \eta_{k}(Y \times A)_{i, k}+\sum_{k=1}^{24} \theta_{k}(M \times A)_{i, k}+\sum_{k=1}^{53} \vartheta_{k}(Y \times M)_{i, k}+\sum_{k=1}^{43} \kappa_{k}(V)_{i, k}
\end{aligned}
$$

where the coefficients $\alpha_{k}, \beta_{k}, \gamma_{k}, \delta_{k}, \zeta_{k}, \varphi_{k}, \eta_{k}, \theta_{k}, \vartheta_{k}$, and $\kappa_{k}$ represent regression coefficients of the $k$ th parameter. The interactions among $Y_{i}, A_{i}$, and $M_{i}$ were treated as random effects whereby $\beta_{k} \sim \mathrm{N}\left(0, \sigma_{1}{ }^{2}\right)$, $\gamma_{k} \sim N\left(0, \sigma_{2}{ }^{2}\right), \quad \delta_{k} \sim N\left(0, \sigma_{3}{ }^{2}\right), \quad \eta_{k} \sim N\left(0, \tau_{1}^{2}\right), \quad \theta_{k} \sim N\left(0, \tau_{2}^{2}\right)$, and $\vartheta_{k} \sim \mathrm{N}\left(0, \tau_{3}{ }^{2}\right)$ while the random effect of vessel $V_{i}$ was treated as an independent term following $\zeta_{k} \sim \mathrm{N}\left(0, \sigma_{4}{ }^{2}\right)$ and $\kappa_{k} \sim \mathrm{N}\left(0, \tau_{4}{ }^{2}\right)$ to avoid having too many parameters. The fixed effect of $h_{i}$ employed the logarithm, but not that of $C_{i}, D_{i}$, and $E_{i}$ when considering goodness of fit measures (Tables $\mathrm{S} 1 \& \mathrm{~S} 2$ in the Supplement at www.int-res.com/articles/suppl/ m617p265_supp.pdf). The second and third operation models used data from $>0$ chub mackerel catches in the first and second operations $(\mathrm{n}=5830$ and $n=2896$, respectively). The parameters were estimated using the glmer function provided in the lme4 package of $\mathrm{R}$ statistical analysis software ( $\mathrm{R}$ Development Core Team 2017).

An additional GLMM was constructed to predict the catch amount $F_{j}$ during each operation (catch model), where $j$ is the serial number of total operations. The catch model used all the data from $>0$ chub mackerel catches from the first, second, and third operations $(\mathrm{n}=9497)$. The potential explanatory vari- 
ables for the catch model were the categorical variables $G_{j}$ and $H_{j}$, which were set at 1 if the operation was the second and third operation, respectively. The interactions among $Y_{j}, A_{j}$, and $M_{j}$ and the independent term $V_{j}$ were also incorporated as random effects. We assumed that $F_{j}$ follows a gamma distribution as $F_{j} \sim \operatorname{Gamma}\left(\mu_{j}, \rho\right)$, where $\mu_{j}$ represents the expected value and $\rho$ is the parameter controlling the variance in $F_{j}$ as $\mu_{j}^{2} / \rho$. The log of $\mu_{j}$ was described as follows:

$$
\begin{aligned}
& \log \left(\mu_{j}\right)=\lambda_{0}+\lambda_{1} G_{j}+\lambda_{2} H_{j}+\sum_{k=1}^{15} v_{k}(Y \times A)_{j, k} \\
& +\sum_{k=1}^{24} \xi_{k}(M \times A)+\sum_{k=1}^{57} \mathrm{o}_{k}(Y \times M)_{j, k}+\sum_{k=1}^{43} \rho_{k}(V)_{j, k}
\end{aligned}
$$

where coefficients $\lambda_{k}, v_{k}, \xi_{k}, o_{k}$, and $\rho_{k}$ represent regression coefficients. The coefficients of random effects follow $v_{k} \sim \mathrm{N}\left(0, \omega_{1}{ }^{2}\right), \xi_{k} \sim \mathrm{N}\left(0, \omega_{2}{ }^{2}\right), \mathrm{o}_{k} \sim \mathrm{N}\left(0, \omega_{3}{ }^{2}\right)$, and $\rho_{k} \sim \mathrm{N}\left(0, \omega_{4}{ }^{2}\right)$. While the second and third operation models were treated as independent models, the catch model was used for predicting the amount of catches in any operation. Because the logbook data showed that most second and third operations were performed at almost the same position as the first operations, we considered that the random effects could be common among the first, second, and third operations. No effects from the effort restrictions were included because the amount of chub mackerel catches would not be affected by their implementation.

Model selection was performed based on biascorrected Akaike's information criterion (AICC) (Burnham \& Anderson 2002). First, the AICc values were compared among the models including all the fixed effects and different sets of random effects to select a combination of random effects whose AICC values were the lowest. The procedure to select the random effects was conducted by using stepwise backward model selection. We also tested the model with the random effects of $Y_{i}, A_{i}$, and $M_{i}$ as independent terms, but those independent terms were not selected. The model selections among the fixed effects were conducted among all the possible combinations of fixed effects and the selected combination of random effects.

Throughout the analysis, because there are no reliable data, we did not consider any zero-catch situations in which purse seiners conducted their operation to target chub mackerel but failed to catch any. However, we considered that such a situation would be minor (but not zero) because of the nature of purse seine fishery; purse seiners generally place their nets only when they identify schools of fish. Our unpublished data also show that almost all the second and third operations in the studied fishery stayed at the position of the first operation, so they caught fish from the same school as the previous operation.

\subsection{Stochastic simulation for quantifying the outcomes of effort management}

We simulated the daily purse seine operations and catches using models with the estimated parameters in Eqs. (1) to (3). As a primary simulation, the daily purse seine operations and catches were randomly generated based on Eqs. (1) to (3), which were expected to match the observed data. As a counter simulation, the explanatory variables of the effort restrictions $\left(h_{i}, g_{i}\right.$, and $\left.f_{i}\right)$ were replaced with artificial values assuming looser restrictions. The duration during which fishers were allowed to conduct purse seine operations $\left(h_{i}\right)$ was set at $15 \mathrm{~h}$ to correspond to the observed maximum value. A sensitivity analysis was also performed using $24 \mathrm{~h}$ instead of $15 \mathrm{~h}$. For the variables $g_{i}$ and $f_{i}$, all the values were set at 0 (there were no upper limits on the daily total number of operations per vessel). The stochastic simulations were repeated 1000 times, and each replication was expressed with a superscript $m$. The stochastic variables $s o_{i}^{m}$ and $t o_{i}^{m}$ were generated using Eqs. (1) \& (2), respectively. The total numbers of operations per day and ship were calculated by 1 $+S O_{i}^{m}+S O_{i}^{m} t o_{i}^{m}$ at the $m$ th simulation. Catches during the first, second, and third operations were generated by Eq. (3) as $F_{j+1}, F_{j+2}$ and $F_{j+3}$, and the total catches per day and ship $C_{i}^{m}$ were expressed as $F_{i, 1}^{m}+$ $s O_{i}^{m} F_{i, 2}^{m}+s O_{i}^{m} t o_{i}^{m} F_{i, 3}^{m}$.

The effects of the effort restrictions were evaluated by comparing the predicted catches between the 2 scenarios. The rate of catch increase (CR) was defined as the rate of predicted total catches under the looser effort restriction scenario $\left(\Sigma C_{i}^{\prime m}\right)$ to those in the current effort restriction scenario $\left(\Sigma C_{i}^{m}\right)$ as $\frac{\Sigma C_{i}^{\prime m}}{\Sigma C_{i}^{m}}$. The summation was conducted throughout the entire study period (entire CR) or by each month and year (monthly CR). The CR quantifies the effectiveness of the current effort restriction; a higher CR indicates more effective effort management. We also calculated the Gini index of the monthly catch distribution to determine the effect on the temporal catch concentration (Birkenbach et al. 2017). The Gini index is a measure of equality. The value increases when the catches are distributed more evenly. 


\section{RESULTS}

The fishing grounds of the chub mackerel varied by seasonal migration along the coast between $36^{\circ} \mathrm{N}$ and $41^{\circ} \mathrm{N}$ (Fig. 2). The fishing grounds extended north during the summer and autumn and moved south during the winter and spring. The seasonal migration of chub mackerel and the corresponding fishing grounds are known to be driven by seasonal changes in the sea surface temperature (Watanabe et al. 2012).

The effort restrictions implemented during the study period were frequently adjusted by the NPFPS and varied spatiotemporally depending on the fishing conditions (Fig. 3). Except for the prohibited area around the Fukushima nuclear plant accident, some restrictions on daily operations have been applied to almost all the fishing areas (Fig. 3A). An upper limit on the total operation number was set at approximately half of the fishing days (Fig. 3B). The most frequent upper limits were 2 (670 total days) to 3 (825 total days). Regarding the hours when the purse seine operations were allowed to commence, 9-10, 11-12, and 13-15 h frequently occurred during the first half of the study period, while 5-6 and 7-8 $\mathrm{h}$ became the dominant hours during the second half. The average hours allowed decreased throughout the study period from 10.2 , to $8.8,7.8,8.1$, and $7.1 \mathrm{~h}$ from 2009-2013, indicating that the effort restrictions became stricter in later years.

The total number of purse seine operations varied by season and year (Fig. 4), increasing during the fishing season from autumn to winter. The total number of the first purse seine operation catching $>0$ mackerel was 6235. Approximately half of the ships conducting the first operations also caught $>0$ mackerel on a second operation, and approximately $10 \%$ caught mackerel on a third operation on the same fishing day. Most third operations tended to occur during the autumn to winter fishing seasons.

We show the results of the GLMM model selection with a sensitivity analysis using different variable transformations (log or normal scale) (Tables S1 \& S2) and residual plots (Fig. S1 in the Supplement). Through the model diagnostics and model selection, it is confirmed that there were no serious flaws in the results of our statistical analyses. In addition, there were no serious over- or under-dispersions in the second and third operation models (Tables S1 \& S2).

The numbers of permitted hours $\left(h_{i}\right)$ had significant positive effects of 1.12 and 1.90 for the second and third operation models, respectively (Table 1). These results suggest that the probability of second
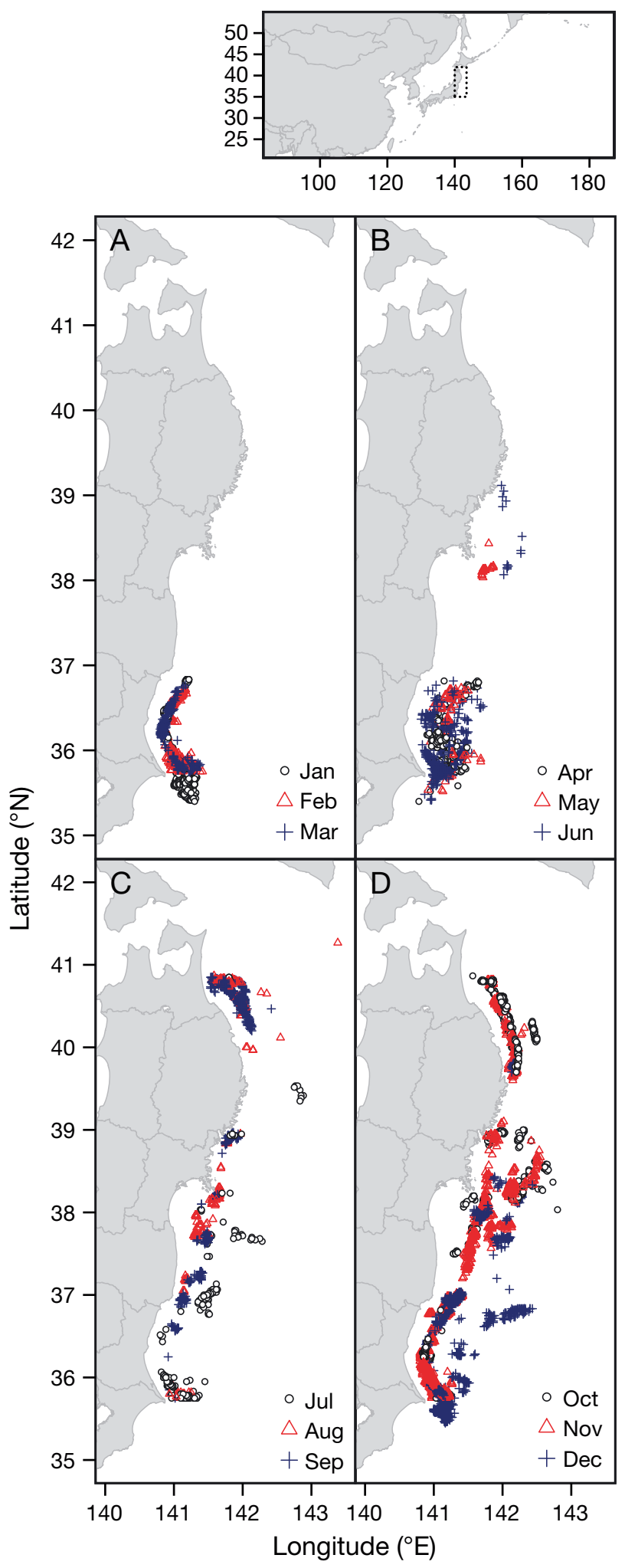

Fig. 2. Quarterly positions of the purse-seine operations with >0 mackerel catches during the 2009-2013 fishing years, defined as running from 1 July to the end of June of the following year. (A) January-March, (B) April-June, (C) July-September, and (D) October-December 

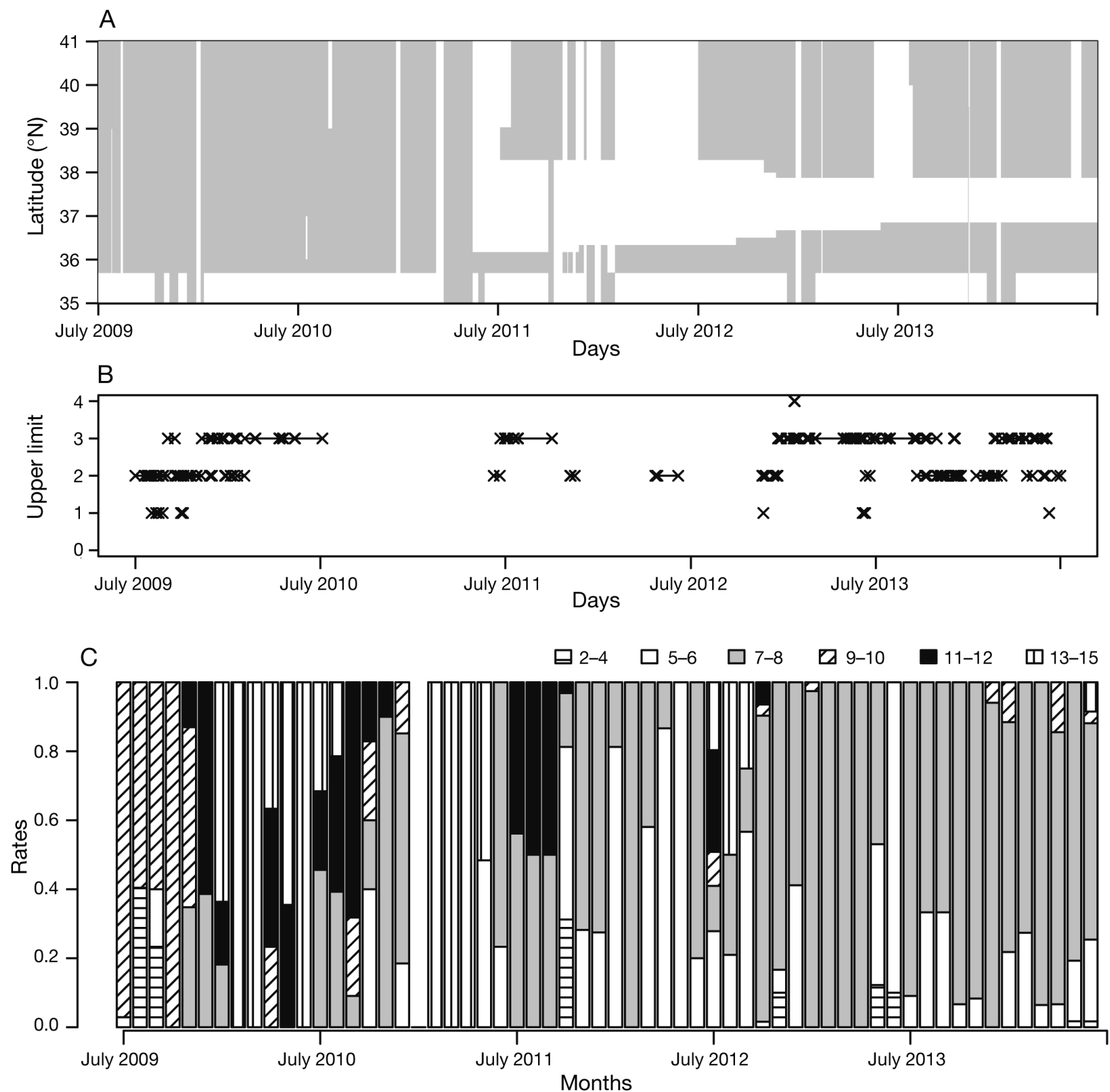

Fig. 3. Implementation of effort management by the North Pacific Federation of Purse Seiners. (A) Fishing area where any effort restrictions on daily purse seine operations were applied (gray shaded area). (B) Upper limit on the total number of daily purse seine operations per vessel. No symbols indicate no upper limits. (C) Hours during which the purse seine operations were allowed to commence. The hours are indicated as the ratio of days when each limitation was applied to the total working days

and third operations with $>0$ mackerel catches increased as the permitted hours increased, thereby confirming that the effort restrictions worked to reduce the number of purse seine operations. We also obtained nearly expected results for the effects of the upper limit of operations $\left(g_{i}\right.$ and $\left.h_{i}\right) ; g_{i}$ had a significant negative effect of -3.00 in the third operation model and $f_{i}$ did not affect either model. Although $g_{i}$ was selected for the second operation model with the lowest AICc, we could not completely reject an alternative model without the $g_{i}$ because of the small $\triangle \mathrm{AICC}$ of 0.9 (Table S1). In addition, the $\triangle \mathrm{AICc}$ of the other 2 models with the different sets of $g_{i}$ and $f_{i}$ were also less than 2 (Table S1). These results suggest that the fisher decisions might be affected by the upper limit restriction even if their operation did not reach the upper limit. We have conducted sensitivity analyses with the alternative models on small AICc differ- 


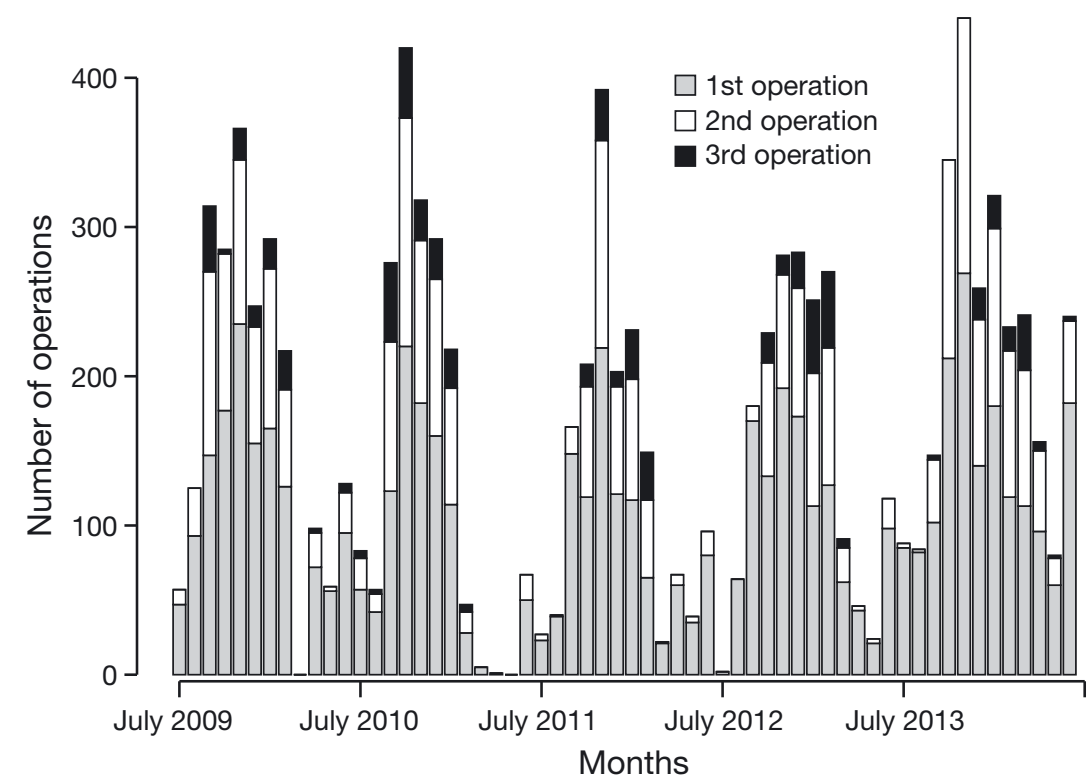

Fig. 4. Monthly total numbers of purse seine operations catching chub and spotted mackerel

ences in the following simulations to evaluate the management effects.

The other factors affecting the second and third operations were the proportion of non-zero chub mackerel catches $\left(E_{i}\right)$ and the total amounts of mackerel catches from the previous operations $\left(C_{i}\right.$ or $\left.D_{i}\right)$. The estimated parameters of $E_{i}$ were negative values and significantly different from zero. Thus, the second and third operations were less likely to be conducted when the proportion of non-zero chub mackerel catches increased. This is probably because of the carrying capacity of the transport ships. In addition, the standard deviations of the random effects were significant and ranged from 0.32 to 1.04 , suggesting that the motivations to conduct the second and third operations changed by season, year, and vessel.

The best model with the minimum AICc for the catch model contained the random effects of $M \times A, Y \times M$, and $V$, and the fixed effects of $G_{i}$ and $H_{i}$ (Table 2, Table S3). We were unable to obtain converged results when using all the random effects, which indicated that the models with all the random effects are over-parameterized and inappropriate. We conducted the model selection except for the full set of random effects. The positive parameters of $G_{i}$ and $H_{i}$ indicated that the catch from the second and third operations tended to be higher than that of the first operation.

The stochastic simulations revealed the quantitative effects of the effort restrictions by contrasting the scenarios with the implemented restrictions and those under looser ones (Fig. 5, Fig. S2 in the Supplement). For the first operations, there were no differences between the 2 scenarios as we assumed (Fig. 5A,B). For the second operations, the total numbers of the purse seine operations and their mackerel catches increased by approximately 1.3-fold

Table 1. Parameters estimated in the second and third operation models with $95 \%$ credible intervals of posterior distributions. NS: not selected: SD: standard deviation

Explanation

Fixed effects

Coefficient

$\log \left(h_{i}\right)$, hours allowed for operations

$g_{i}=1$ when the upper limit of the total number

of operations per ship and day is 2

$f_{i}=1$ when the upper limit of the total number

of operations per ship and day is 3

$C_{i}$ (catch in the first operation) for the second operation model or $D_{i}$ (total catch in the first and second operation) for the third operation model

$E_{i}$ proportion of non-zero chub mackerel catches

\section{Random effects}

SD of $Y \times A$ (year and area)

SD of $M \times A$ (month and area)

SD of $Y \times M$ (year and month)

SD of $V$ (vessel) $\begin{array}{ccc}\text { Second operation model } \\ \text { Parameter } & \text { Estimate } \quad 2.5 \% \quad 97.5 \%\end{array}$
Third operation model
Parameter Estimate $\quad 2.5 \% \quad 97.5 \%$ 
Table 2. Parameters estimated in the catch model with $95 \%$ credible intervals of posterior distributions. NS: not selected; SD: standard deviation

\begin{tabular}{|lcccc|}
\hline Explanation & Parameter & Estimate & $2.5 \%$ & $97.5 \%$ \\
\hline $\begin{array}{l}\text { Fixed effects } \\
\quad \text { Coefficient }\end{array}$ & $\lambda_{0}$ & 1.35 & 1.14 & 1.56 \\
$\quad \begin{array}{l}G_{i}=1 \text { when the operation was } \\
\text { the second operation }\end{array}$ & $\lambda_{1}$ & 0.08 & 0.04 & 0.13 \\
$\quad H_{i}=1$ when the operation was & & & & \\
$\quad$ the third operation & $\lambda_{2}$ & 0.31 & 0.21 & 0.42 \\
$\quad$ Random effects & & & & \\
SD of $Y \times A$ (year and area) & $\omega_{1}$ & & & \\
SD of $M \times A$ (month and area) & $\omega_{2}$ & 0.24 & 0.19 & 0.32 \\
SD of $Y \times M$ (year and month) & $\omega_{3}$ & 0.57 & 0.57 & 0.76 \\
SD of $V$ (vessel) & $\omega_{4}$ & 0.09 & 0.07 & 0.10 \\
\hline
\end{tabular}

(Fig. 5C,D), and those in the third operations increased by approximately 2.6-fold (Fig. 5E,F) under the looser effort restriction scenario compared with the current scenario. Overall, the rate of catch increase during the entire study period (entire CR) was 1.17 in the base scenario with a $15 \mathrm{~h}$ time limitation (Fig. 5G,H) and 1.28 in the sensitivity analysis with a $24 \mathrm{~h}$ limitation (Fig. S2). The entire CR was not sensitive to alternative second operation models with different sets of fixed effects for $g_{i}$ and $f_{i}(\mathrm{~F} 2, \mathrm{~F} 3$, and F4 in Table S1 in the Supplement) because the entire CR rarely ranged between 1.16 and 1.17

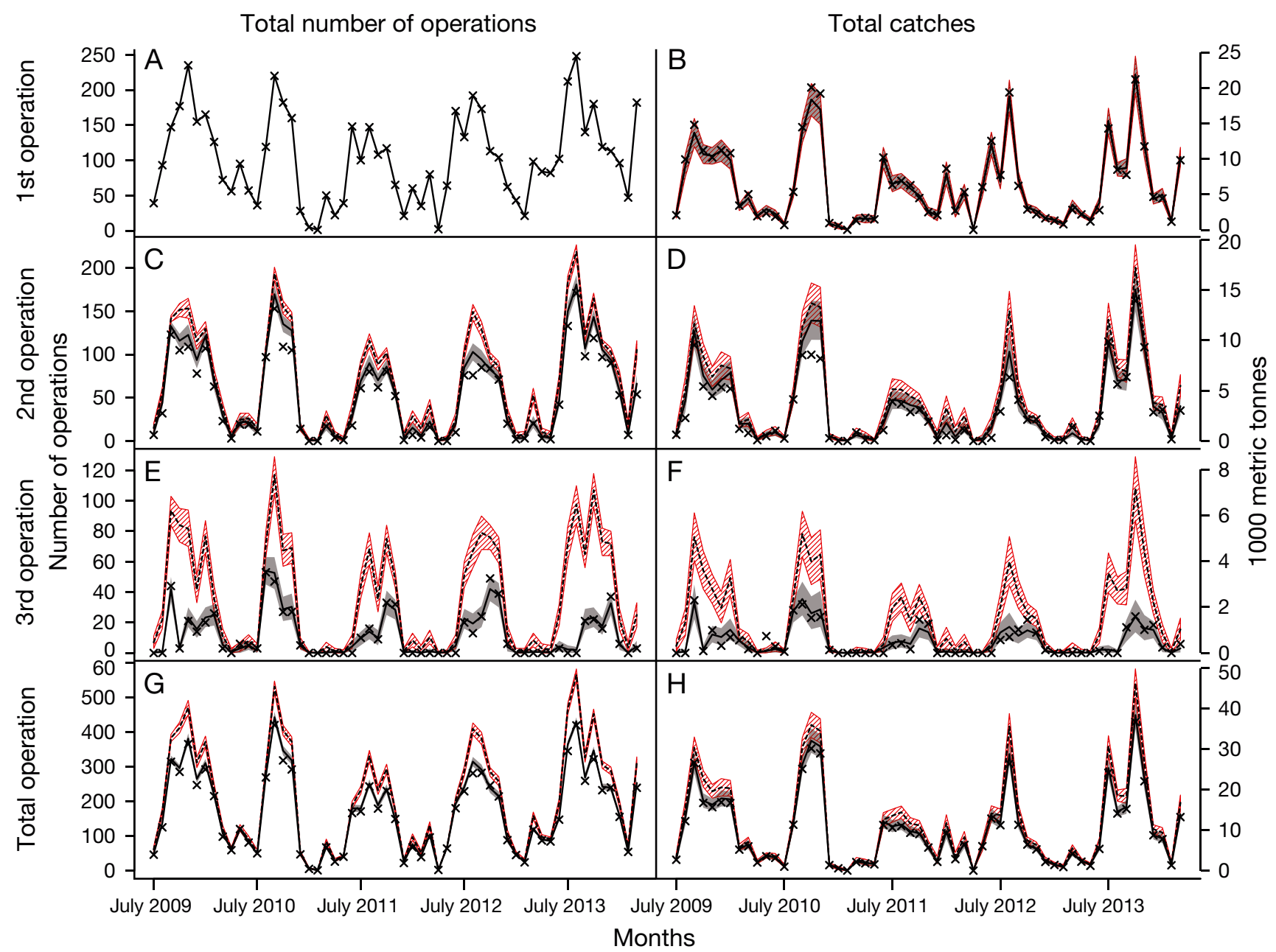

Fig. 5. Total numbers of operations (left) and total catches (right) by (A, B) first, $(C, D)$ second, $(E, F)$ third, and $(G, H)$ total operations, as generated from stochastic simulations based on the parameters estimated in generalized linear mixed models. Predictions under the existing effort restrictions (gray shaded area) and those under looser effort restrictions (with an upper limit of operation hours of $14 \mathrm{~h}$ and no limits for the total number of operations; hatched area with red colors) were compared. Crosses represent the observed values. Shaded or hatched areas represent the 90th percentiles, and solid and broken lines 
when using the alternative models and assuming $h_{i}=15$.

The rates of catch increase by month (monthly CR) varied temporally from 1 to 1.5 in the base case scenario of $h_{i}=15$ and tended to increase during the fishing seasons with higher catches (Fig. 6). These results suggest that the effort restrictions were not effective during non-fishing seasons when their catches and efforts were originally expected to be low. Thus, if the effort restrictions were looser, their catches might become more concentrated during a good fishing season. The Gini indices of simulated monthly catches under looser effort restrictions were estimated to decrease to $0.54\left(h_{i}=24\right)$ and $0.56\left(h_{i}=\right.$ 15) from the value under the actual effort restrictions $(0.58)$. The effects of the catch reductions also varied by year. The average catch increase rates were $1.07-1.21,1.12-1.26,1.18-1.31,1.16-1.30$, and 1.151.30 (assuming $h_{i}$ as 15-24 h) from 2009-2013, respectively. These rates corresponded to the observed decrease in average hours allowed from $10.2 \mathrm{~h}$ in 2009 to $7.1 \mathrm{~h}$ in 2013.

\section{DISCUSSION}

Our results provided quantitative answers to our initial questions. First, the effort management restricting daily purse seine operations was found to reduce the total number of operations significantly (Table 1). Second, stochastic simulations under looser effort restrictions revealed that the reduction in total purse seine efforts subsequently contributed to a reduction in chub mackerel catches by approximately $20 \%$ (Figs. $5 \& 6$ ). The effort restrictions were particularly successful in reducing third operations (Fig. 5C-F). This finding is consistent with the fact that the average duration of a purse seine operation was $2-3 \mathrm{~h}$ (NPFPS unpubl. data), while $7-8 \mathrm{~h}$ was the most frequently observed duration allowed during the study period (Fig. 3). These results indicate best practice, in which the effort management effectively helped avoid overshooting of the quota and consequent seasonal closures, in the purse seine fishery targeting small pelagic fish.

This simulation study demonstrated that the quantitative effects of the effort restrictions depended on the assumption of 'baseline conditions without effort management'. According to our results, there was little motivation to conduct the second and third operations during the non-fishing season for chub mackerel in the studied fishery. As a result, no increase in catch and effort would have occurred even if there had been no effort restrictions. However, if a more extreme situation had occurred, whereby each fleet conducted 3 operations during each cruise under no effort management, the effects would have been over-estimated. A sensitivity analysis assuming that all purse seine cruises conducted 3 operations revealed a 1.6-fold increase in total catches and effort, although this assumption would be unrealistic. This study set a more realistic baseline based on statistical models and observed data, providing a more conservative evaluation.

In our previous study, we evaluated the effects of day closures in the same fishery during 2004-2008

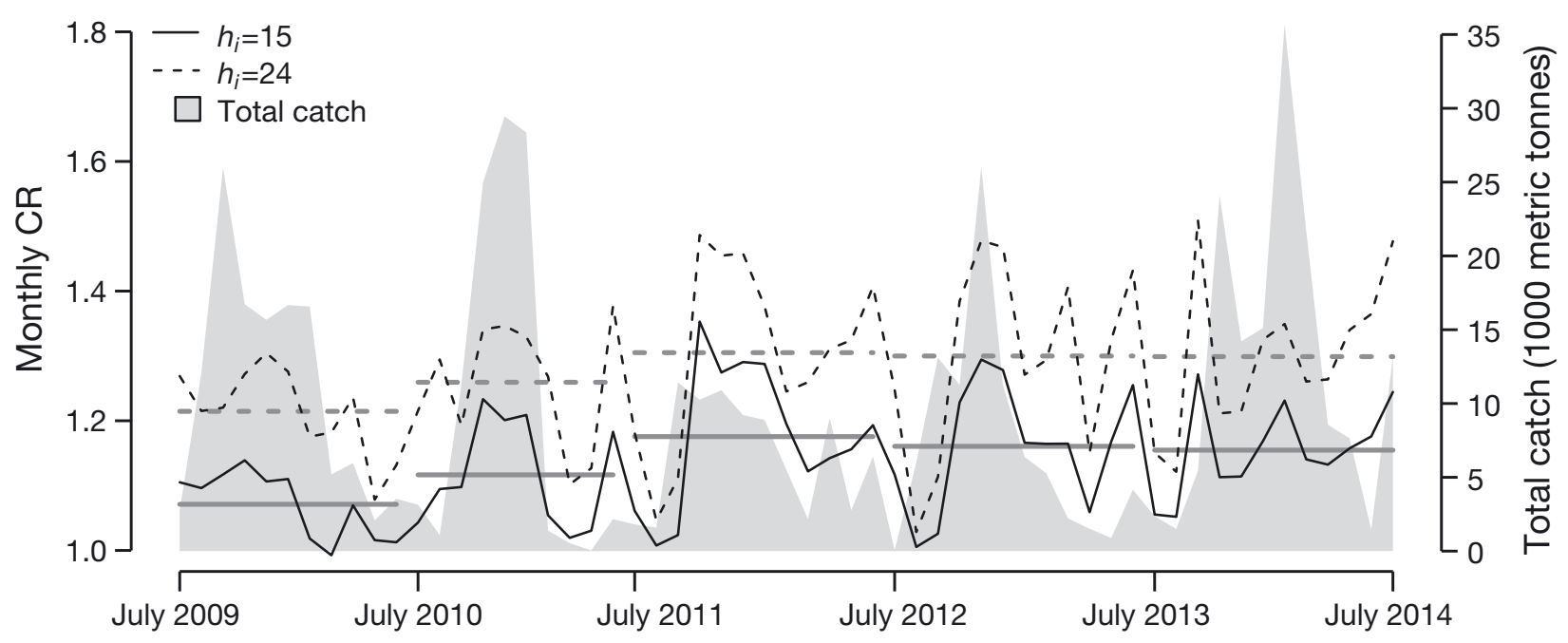

Fig. 6. Rate of predicted total monthly catches in the looser effort restriction scenario $\left(h_{i}=15\right.$ or 24$)$ relative to those in the current restriction scenario (monthly $C R$, left axis). The observed catches are also indicated by the gray shaded area (right axis). The horizontal gray solid and broken lines represent averages for the monthly CR by year 
fishing years using a similar methodology (Ichinokawa et al. 2015). The number of working vessels in a single fishing day was then modeled as a stochastic process, and the effects of day closures were evaluated by predicting the expected number of working vessels without day closures. While the previous study did not explicitly model the purse seine operations of each vessel on an individual fishing day, the present study modeled it as a sequential stochastic process (first to third fishing operations). Together, the 2 studies provide a complementary evaluation of effort management in the form of both day closures (Ichinokawa et al. 2015) and daily restrictions on purse seine operations (this study) although the study periods of the 2 studies were different due to the limited data availability. Ichinokawa et al. (2015) estimated that day-closure management resulted in a catch reduction of approximately $10 \%$. Then, the total effects of the effort management system on the catch reductions was estimated as approximately $28 \%([1-0.8 \times 0.9] \times 100)$ when assuming the effects of individual management methods were independent and time invariant. In the absence of the effort management system, this fishery would have overshot its quota because the percentage of the quota uptake was $60-80 \%$ during the study period. We therefore conclude that the effort management system examined here helped to prevent seasonal fishing closures due to overshooting the quota, which are often induced by the race-to-fish under global quota management alone.

The fishing conditions for chub mackerel in the study fishery are known to vary by temporally changing oceanographic conditions and autocorrelation (Ichinokawa et al. 2015). These temporally changing fishing conditions would make it difficult to adjust the total catch within a given quota while avoiding fishery closures resulting from overshooting. The current under-consumption of the quota is attributed to the characteristics of the studied fishery. Because the fishers in this fishery seemed to prefer fishing yearround rather than engaging in the efficient uptake of their quota in recent years, these strict effort restrictions could be implemented to maintain an annual total catch below the annual allocation with high certainty.

This study did not model all the potential complicated interactions considered in the fisheries dynamics. For example, this study only evaluated the instantaneous reduction rates in catches occurring after the first operation, and did not consider the stochastic process of the first operation. Longterm interactions between stock abundance and catches are also important in the future because an increase in the catches would decrease the total biomass, resulting in a decrease of catch per unit of effort. In addition, we did not test the effect of day closures implemented during the study period on the probabilities of the second and third operations because there were no available data. Although our previous study (Ichinokawa et al. 2015) did not find strong statistical evidence for increases in fishing efforts and catches on the day just after these closures, further detailed examination on interactions among different types of management methods would be important. Finding and modeling potential interactions among fishing efforts, biomass, catches, and management implementation can contribute to a quantitative evaluation of the long-term effects on stock dynamics (Ichinokawa et al. 2015). A future study should be extended to include all possible elements and to conduct complementary analyses.

The present study also found that the effort restrictions could contribute to reductions in the catch concentration (Fig. 6). Birkenbach et al. (2017) revealed that the introduction of catch shares in the United States significantly reduced the Gini index of the monthly catch distribution by an average of $9 \%$. Here, the Gini index was reduced by an estimated $3-7 \%$ in response to the effort restrictions. Although the estimated reduction rates were slightly lower than the expected value in catch shares, they showed that effort management could contribute to a reduction in the race-to-fish behavior as with catch shares. Because the price of fish was known to decrease when the amount of catches increased in the studied fishery (Makino 2011), the reduction in the Gini index is expected to contribute to increases in the price of fish and thus in profits.

Management objectives are diverse, and therefore, management tools should also be diverse depending on the management objectives. This study examined the quantitative outcomes of properly designed effort management as implemented in a Japanese purse seine fishery. The effort management resulted in the inefficient uptake of the quota but secured year-round operations to avoid overshooting the quota even under temporally variable fishing conditions. These outcomes are different from the ones usually expected by catch share management, namely, the efficient uptake of the quota and the maximization of profit. It is important to recognize that we can choose a variety of management tools and we can evaluate the outcomes of each management strategy scientifically. 
Acknowledgements. We thank the NPFPS for compiling and providing daily catch and effort data. We are grateful to the organizers of the international symposium of 'Drivers of dynamics of small pelagic fish resources' in Victoria, BC, Canada from 6 to 11 March 2017. The symposium provided the motivation for us to finalize this study. We also thank all the participants at the symposium and 3 anonymous reviewers for their useful comments on this study. This work was supported by the JSPS KAKENHI under Grant Number JP15K18737.

\section{LITERATURE CITED}

Beddington JR, Agnew DJ, Clark CW (2007) Current problems in the management of marine fisheries. Science 316:1713-1716

Birkenbach AM, Kaczan DJ, Smith MD (2017) Catch shares slow the race to fish. Nature 544:223-226

Branch TA, Hilborn R, Haynie AC, Fay G and others (2006) Fleet dynamics and fishermen behavior: lessons for fisheries managers. Can J Fish Aquat Sci 63:1647-1668

Burnham KP, Anderson DR (2002) Model selection and multimodel inference: a practical information-theoretic approach. Springer, New York, NY

Costello C, Gaines SD, Lynham J (2008) Can catch shares prevents fisheries collapse. Science 321:1678-1681

Edwards CTT, Dankel DJ (2016) Management science in fisheries: an introduction to simulation-based methods. Routledge, London

Fisheries Agency and Fisheries Research Agency of Japan (2017) Marine fisheries stock assessment and evaluation for Japanese waters (fiscal year 2016/2017). http:// abchan.fra.go.jp/digests28/index.html (accessed 2 March 2018) (in Japanese)

Fulton EA, Smith ADM, Smith DC, van Putten IE (2011) Human behaviour: the key source of uncertainty in fisheries management. Fish Fish 12:2-17

Hardin G (1968) The tragedy of the commons. Science 162: 1243-1248

KHilborn R, Orensanz JM, Parma AM (2005) Institutions, incentives and the future of fisheries. Philos Trans R Soc Lond B Biol Sci 360:47-57

Hillary R, Preece A, Davies C, Kurota H and others (2016) A scientific alternative to moratoria for rebuilding depleted international tuna stocks. Fish Fish 17:469-482

Ichinokawa M, Okamura H, Watanabe C, Kawabata A, Oozeki Y (2015) Effective time closures: quantifying the conservation benefits of input control for the Pacific chub mackerel fishery. Ecol Appl 25:1566-1584

Katsukawa T (2005) Evaluation of current and alternative fisheries management scenarios based on spawning-perrecruit (SPR), revenue-per-recruit (RPR), and yield-perrecruit (YPR) diagrams. ICES J Mar Sci 62:841-846

Kawai H, Yatsu A, Watanabe C, Mitani T, Katsukawa T, Matsuda H (2002) Recovery policy for chub mackerel

Editorial responsibility: Olivier Thébaud (Guest Editor), Plouzane, France stock using recruitment-per-spawning. Fish Sci 68:963-971

* Lester SE, Halpern BS, Grorud-Colvert K, Lubchenco J and others (2009) Biological effects within no-take marine reserves: a global synthesis. Mar Ecol Prog Ser 384:33-46

*Lluch-Belda D, Crawford RJM, Kawasaki T, MacCall AD, Parrish RH, Schwartzlose RA, Smith PE (1989) Worldwide fluctuations of sardine and anchovy stocks: the regime problem. S Afr J Mar Sci 8:195-205

* Ludwig D, Hilborn R, Walters C (1993) Uncertainty, resource exploitation and conservation: lessons from history. Science 260:17-36

Makino M (2011) Fisheries management in Japan: its institutional features and case studies. Springer, Dordrecht

Morgan GR (1997) Individual quota management in fisheries - methodologies for determining catch quotas and initial quota allocation. Food and Agriculture Organization of the United Nations, Rome

\% Okamura H, Ikeda S, Morita T, Eguchi S (2016) Risk assessment of radioisotope contamination for aquatic living resources in and around Japan. Proc Natl Acad Sci USA 113:3838-3843

Pope J (2009) Input and output controls: the practice of fishing effort and catch management in responsible fisheries. In: Cochrane KL, Garcia S (eds) A fishery manager's guidebook. Food and Agricultural Organization of the United Nations, Rome, and Wiley-Blackwell, Chichester, p 220-252

Nevelopment Core Team (2017) R: a language and environment for statistical computing. R Foundation for Statistical Computing, Vienna. www.r-project.org

* Rijnsdorp AD, Daan N, Dekker W, Poos JJ, Van Densen WLT (2007) Sustainable use of flatfish resources: addressing the credibility crisis in mixed fisheries management. J Sea Res 57:114-125

Salas S, Gaertner D (2004) The behavioural dynamics of fishers: management implications. Fish Fish 5:153-167

* Watanabe C, Suda M, Akamine T, Kawabata A, Nishida H (2012) Effects of spatio-temporal allocation of allowable catch on the population dynamics of the Pacific stock of chub mackerel. Bull Jpn Soc Sci Fish 78:15-26 (in Japanese with English abstract)

Wilen JE (1979) Fisherman behavior and the design of efficient fisheries regulation programs. J Fish Res Board Can 36:855-858

Yukami R, Watanabe C, Kamimura Y, Furuichi S, Akamine T, Kishida S (2017a) Stock assessment of the Pacific stock of Japanese sardine in fiscal 2016 year. In: Marine fisheries stock assessment and evaluation for Japanese waters. Fisheries Agency of Japan and Fisheries Research Agency, p 15-52 (in Japanese)

Yukami R, Watanabe C, Kamimura Y, Kishida S (2017b) Stock assessment of the Pacific stock of chub mackerel in fiscal 2016 year. In: Marine fisheries stock assessment and evaluation for Japanese waters. Fisheries Agency of Japan and Fisheries Research Agency, p 154-200 (in Japanese)

Submitted: September 18, 2017; Accepted: July 3, 2018 Proofs received from author(s): August 27, 2018 